\title{
Experience of Health Workers in the Implementation of Adolescent Friendly Health Services (AFHS) in Magelang
}

\author{
Rohmayanti $^{1}$, Suryo Ediyono ${ }^{2}$ \\ \{rohmayanti@ummgl.ac.id $\left.{ }^{1}\right\}$ \\ Maternity Nursing of Department, Universitas Muhammadiyah Magelang, 56172, Indonesia ${ }^{1}$ \\ Cultural Science of Department, Universitas Sebelas Maret, 57126 , Indonesia ${ }^{2}$
}

\begin{abstract}
The aim of this study was to explore the experiences of health workers in the implementation of AFHS in Magelang City. This study was a qualitative study using phenomenology method. The sampling method was a purposive sampling with 6 participants. Data was collected using semi-structured in-depth interviews and observations. The analysis was conducted using Colaizzi. Health workers' experiences on the implementation of AFHS were included obstacles to AFHS implementation and the expectation of the future implementation of AFHS. Emerging themes were (1) internal barrier is limited personnel with limited knowledge, capabilities and time as youth service officers, (2) external barriers to AFHS implementation ((2.1) limited funding, (2.2) lack of cooperation in programs and sectors, (2.3) inadequate facilities for adolescents). (3) The expectations of AFHS implementation included: (3.1) increasing budget, (3.2) services focused on youth counseling: forming a special team of experts, services performed inside and outside the school, service facilities tailored the needs of adolescents, and using multimedia in education, (3.3) cross-program and sectoral involvement in implementation and monitoring resulting in policies that favor teenagers. Conclusion: The results of the study could be used as a reference for improving the quality of AFHS in health centers.
\end{abstract}

Keywords: Experience, health workers, adolescent friendly health services (AFHS)

\section{Introduction}

The results of the 2010 population census in Indonesia, show that 1 in 4 Indonesians are young people aged 10-24 years, of the 240 million Indonesian population, the number of teenagers is large, reaching 63.4 million or around 26.7 percent of the total population. Based on data from the Central Java Statistics Agency [1], the total population of Central Java is 33.27 million, with the number of adolescents aged 10-19 years of 5.8 million or 5.7\% percent of the total population. Meanwhile, the population of Magelang City in 2012 was 118,909, of which $5.9 \%$ were teenagers. With a large number of adolescents, adolescents face various problems in the life of the adolescent world.

Adolescence is a healthy period but also when individuals face a greater risk of morbidity and mortality associated with violence and sexual and reproductive health [2]. Health services can have a beneficial impact on adolescent health, by providing good information to adolescents, caring for those who are sick and reaching those in vulnerable situations [3]. However, research shows that young people face significant barriers to accessing health services. although 
adolescents recognize the importance of accessing AFHS, they are less likely to utilize services because of stigma [4]. Cultural barriers include the trust and stigma of society, and the knowledge of youth, and facilitators. Structural barriers include financial costs, distance to health facilities, waiting times, and lack of supplies and medicines. Feelings of fear, shame and discomfort are barriers associated with 'accueil' while interaction with health workers is a barrier to facilitators [5]. On the other hand, health professionals tend to prioritize youth consultation less.

Youth-friendly health services (AFHS) are defined as services that are accessible, acceptable, fair, appropriate and effective. Youth-friendly healthcare workers are an important component of AFHS, and require specific competencies (describe the knowledge and skills to carry out the roles and responsibilities they need, and an assessment of whoever) and attitudes to provide evidence-based, non-judgmental and non-discriminatory care, especially with regard to sexual and reproductive health (SRH). In particular, they must be able to consider the cognitive, emotional, and social capacities of adolescents, and to understand and evaluate each adolescent as an individual at a particular development point in a unique social context [2]. In addition, health workers must have a clear understanding of their roles and responsibilities, be supported to take them out, and be responsible for doing so [3].

Although there have been several studies on the perspectives of health workers in AFHS, several studies have investigated how young people desire the health services provided by health workers to adolescents [1]. There is extensive evidence showing that the performance of health workers in low- and middle-income countries is often inadequate [6]. Moreover, despite the acknowledgment of the important role of health workers in the provision of AFHS, there is little evidence synthesized on the role of health workers that comply with standards in providing youth friendly services (AFHS) especially in Primary Health Care Service (PHCs). Therefore, this study seeks to explore how the experiences of health workers in implementing adolescent care health services at PHCs.

\section{Method}

A fenomenology qualitative study was conducted between September and October 2015 in Magelang, Central Java, Indonesia. The study protocol was approved by the Ethics Committee of Universitas Muhammadiyah Magelang. Four health worker, one doctor and one public health expert from the health department because of their experience and knowledge of providing AFHS. The participants were selected through purposive sampling from five purposively selected Primary Health-Care Centers in Magelang City. Purposive sampling was used because there are only four Primary Health Center. Semi-structured interviews and observation, were conducted with all participant, which were conducted in Indonesia, after consent was obtained. The recorded interviews were transcribed verbatim and analyzed thematically (Braun \& Clarke, 2006). This included familiarization by reading and re-reading the transcriptions, generating initial codes, generating, defining and reviewing themes, and finalizing the analysis. Rigour was applied through credibility, dependability and transferability (Guba, 1981). The principal researcher developed the initial codes which were then discussed with the research supervisor to reach a consensus. A list of codes and their definitions was compiled which were revised as coding proceeded and new codes included. The codes were reviewed for patterns and developed into themes to address the study objectives. Both 
researchers discussed the themes to reach consensus and their coherence in representing the data.

\section{Results and Discussion}

Magelang City was chosen to be the research site because all PHCs have been running the PKPR program since 2011, apart from that all PHCs in Magelang City are in the process of becoming a Regional Public Service Agency so that services to the community are better. The number of main PHCs in Magelang City is 5 units and 11 smal of units.

\subsection{Participants' characteristics}

The participants included five females and one male. They were married and all off them were Muslims (Table 1).

Table 1. Characteristics of key informants

\begin{tabular}{lclll}
\hline \multicolumn{1}{c}{ Location } & Age & \multicolumn{1}{c}{ Sex } & \multicolumn{1}{c}{ Profession } & Marital Status \\
\hline Health Facility A & 35 & Female & Nurse & Married \\
Health Facility B & 36 & Female & Nurse & Married \\
Health Facility C & 33 & Female & Nurse & Married \\
Health Facility D & 35 & Female & Nurse & Married \\
Health Facility E & 53 & Male & Doctor & Married \\
Public Health Office & 49 & Female & Public Health & Married \\
\hline
\end{tabular}

\subsection{Internal barrier to implementing AFHS}

The first obstacles in implementing AFHS are internal constraints, limited personnel with limited knowledge, capabilities and time as youth service officers, to implement and report on programs. Internal obstacle in the form of limited human resources are felt by all participants, only one program holder is the program implementer of these activities, while the health worker also holds other program activities.

"Regarding the service, there are limited health personnel and we have submitted it but have not submitted it, and program holders do not focus on youth programs, because there are other programs that are held, so they are also constrained by reporting" (Participant 6, 49 years).

"Our working time is up to 2 in the afternoon, if the activities in SMP 4 are late in the afternoon, it is more than working hours, especially if we go to Karangtaruna it has to be at 9 pm, we cannot afford the time" (Participant 3, 33 years old).

\subsection{External barrier's}

While the second obstacle is external obstacles to the implementation of AFHS, i.e limited operational funds because funds are only from health operational costs (BOK), lack of crossprogram and sector cooperation, inadequate service facilities for adolescents. External obstacles in the form of limited operational funds became the main problem for all participants, the existing funds came from health operational funds amounting to $40 \%$ which could be used for AFHS activities along with other activities. 
"Yes, that's what is clear from the office, for funding there is BOK (health operational costs). If the activity is in the afternoon, it is more than working hours, so the funds used for transport run out." (Participant 1, age 35 years)

"Infrastructure is not very supportive because of limited funds, small funds. if that is not covered by the agency sometimes running the puskesmas. With BOK funds, both from APBD1, APBD 2, sometimes from the center as well but not always "(Participant 6, 49 years old).

"For example, there is no health operational cost fund, I must still be able to run it, there is only BOK funds, it is not only for adolescents, but all programs, and those adolescents also do not enter the MDGs" (Participant 3, age 33).

External obstacles are in the form of a lack of cooperation between programs and sectors, some of them have implemented it due to a shortage of health workers, but there is absolutely no cross-sector cooperation.

"For example, if I have a program here, just cross-program in the health center, for example I need information on HIV AIDS or drugs, then I coordinate with them, or or with midwives for reproductive health but if it has not been implemented cross-sectoral" (Participant 2, age 36 ).

"There is a program from the BKKBN called PIK or something but it seems that there is no collaboration yet, for now our activities are only cross-program" (Participant 4, 35 years old).

External obstacles in the form of inadequate service facilities for teenagers, the available rooms do not meet the criteria for youth-friendly services, some even do not have special rooms, so along with standard general care rooms

"If there are students who have problems, they should be invited to meet them somewhere, because the rooms are standard care, not for teenagers. Sometimes teenagers come but don't come back because they are ashamed "(Participant 1, age 35)

"If we do all the counseling, we also do the inspection activities. But the obstacle is the inadequate infrastructure" (Participant 3, 33 years old)

"The existing room used to be a breast milk counseling room and it was changed for AFHS. If there are teenagers who are put in a room, they become afraid because they are afraid of what the health workers will do "(Participant 4, age 35).

\subsection{Hope for the implementation of AFHS in the future}

The hope of implementing AFHS includes an increase in the budget, the type of service is focused on youth counseling, forming a special team of experts, services are carried out in schools and outside schools, service facilities are adjusted to the needs of adolescents, the need to use multimedia in health promotion, cross-program and sectoral involvement in implementation and monitoring and evaluation so as to produce policies that favor youth.

The hope of the first implementation of AFHS is an increase in the costs allocated specifically for the AFHS program from any fund.

"From the technical guidelines for health operational assistance, $60 \%$ of the funds are for activities that support the MDGs, $40 \%$ for other development, so that large amounts must be exchanged for AFHS activities because of their developmental nature" (Participant 5, age 53).

"The important thing is that our program runs, the important thing is to help youth, thankfully there is more funds so that the program can be maximized" (Participant 4, age 35).

It is hoped that the implementation of AFHS should focus on youth counseling services, inside and outside schools with the use of multimedia in the form of social media or other media.

"If our activities we give counseling, if we want to put more emphasis on adolescents, yes, we give more counseling and it can be done at school and outside of school with SMS or other social media" (Participant 3, age 33 years) 
"In my opinion, we have to be friends for them so that I can get in, in providing counseling, so we focus on counseling, trying not to patronize, and not ordering, implementation can be done in schools and in the academy, for example with various technologies that exist today" (Participant 2, age 36 years).

The hope of implementing AFHS is that there is cross-program involvement and monitoring and evaluation from the local health office.

"For the youth program holder, there is only one person, but when doing so it must be together with other programs, not stand alone but integrated with other programs, all programs must be evaluated and the tone of the follow-up plan from the agency" , 53 years old).

"As much as possible do not be alone, involve cross-programs within the puskesmas, so we see each activity like that, not only AFHS and others, there must be cross-programs, monitoring and evaluation needs to be done, not just a report on paper, so we know what the obstacles are and given joint solutions "(Participant 6, age 49).

\subsection{Discussion}

The results of research on the experience of health workers in implementing AFHS are perceived as an obstacle and hope. They have felt the obstacles from the implementation of the program while interacting with teenagers. These obstacles originate from themselves and are felt from outside themselves. Meanwhile, the participants described the hopes of implementing the AFHS program as a dream for the future in an ideal AFHS program.

To overcome obstacles related to limited human resources, what can be done is to conduct service training for adolescents. Training of health workers is one of the most commonly used interventions to improve health worker performance. It is also one of the most effective interventions for doing so, as determined by the health-care provider performance review. However, evidence clearly suggests that certain types of trainings do not substantially or sustainably improve the competencies or attitudes of healthworkers Careful consideration must be given to the training methodologies, preparation of trainers, location, duration, and group size and composition [3].

In addition, increasing health personnel resources can be overcome by collaborating across programs within one PHCs. In implementing the AFHS program there is a process of introduction, development and preservation of AFHS that takes place in the long term, and requires creative team effort and collaboration between donors, public agencies and health providers. External motivation and support is essential to initiate and sustain the implementation of AFHS. The transformation of health facilities into AFHS is associated with the broader organization of the country's health systems, and the evolution of national youth health policies [7]. In addition, the facilitating factors needed for youth-friendly health services are (1) commitment and priority of health service providers to youth-friendly health services; (2) organizational support; (3) appropriate clinical settings; and (4) external support for youth health promotion activities [6].

One of the needs for health service transformation is to provide facilities that meet the criteria in youth care services. Availability of trained health care providers, adequate privacy, dedicated youth health care team, and adolescent health promotion activities were clinical characteristics that were significantly $(\mathrm{p}<0.05)$ associated with the adolescent friendliness score in the clinic [6]. Apart from facilities, what needs to be developed is the counseling ability of health workers, because in their teens they need to be heard not to be given lectures. The health workers implementing AFHS at PHCs should take a complementary role to replace parents who do not have the skills to guide their adolescents towards responsible sexual behavior. Programs 
need to be developed to enable nurses to optimize their relationships with adolescents and provide services through a mobile health care unit to adolescents with which they regularly socialize. In addition, the use of social media as a communication link must be developed by health workers implementing the AFHS program. Programs need to be developed to enable health workers to optimize their relationships with adolescents and provide services through a mobile health care unit to adolescents with which they regularly socialize. Management should provide a budget for nurses to use multimedia to interact with adolescents. [8]

Funding is important in implementing the AFHS program, because with sufficient funds it will support the achievement of programs in AFHS, limited funds make AFHS not a program in the main priority scale. Limited priority of youth centers by stakeholders and uncertain funding also exacerbates inequality by weakening the health care system. Meanwhile, inadequate medical supplies and medicines, shortages of health workers at the closest health facilities and a weak referral system prevent adolescents from enjoying the maximum health benefits, thus damaging youth welfare or generosity. Inadequate supplies of drugs and drugs and the unavailability of youth-friendly health services at the nearest health facilities not only impact the principles of social justice and generosity ethics but also threaten the privacy, freedom and confidentiality of adolescents and autonomy in health services [9]. In the end, listening to and trying to understand the perspectives of health workers in implementing the AFHS program through their long experience in running the program can help achieve all mandatory programs and will increase youth access to be willing to provide services at PHCs that implement the AFHS program.

\section{Conclusion}

Health workers in Magelang City face considerable related barriers to implementation the AFHS programs, with internal barriers (limited and multi programmed implementing personnel, limited knowledge and capabilities as youth service officers, limited time implementing and reporting programs) and external barriers to AFHS implementation (limited funding, lack of cooperation in programs and sectors, inadequate facilities for adolescents). This paper highlights the need for cross-program and sectoral involvement in implementation and monitoring resulting in policies that favor teenagers. It also emphasizes the need for the provision for increasing budget, services focused on youth counseling, forming a special team of experts, services performed inside and outside the school, service facilities tailored the needs of adolescents, using multimedia in education. Further studies are needed to explore contextual strategies that can create more supportive intersectoral for AFHS to address the limitations. The findings of the current study recommend context specific interventions in Magelang and advocate for policy and legislative direction to improve adolescent access to AFHS services and support healthcare workers in meeting the AFHS needs of adolescents.

\section{Acknowledgement}

The authors wish to thank the management and staff of all the PHCs and all the participants who gave of their time for the current study. 


\section{References}

[1] R. Rohmayanti, I. T. Rahman, and W. A. Nisman, "Pelayanan Kesehatan Peduli Remaja Menurut Perspektif Remaja Di Kota Magelang,” J. Kesehat. Reproduksi, vol. 2, no. 1, pp. 12-20, 2015.

[2] World Health Organization, "Global standards for quality health-care services for adolescents: a guide to implement a standards-driven approach to improve the quality of health care services for adolescents," World Heal. Organ., vol. 1, no. 1, pp. 1-40, 2015.

[3] D. M. Denno, M. Plesons, and V. Chandra-Mouli, "Effective strategies to improve health worker performance in delivering adolescent-friendly sexual and reproductive health services," Int. J. Adolesc. Med. Health, 2020.

[4] A. G. Nmadu, S. Mohamed, and N. O. Usman, "Adolescents' utilization of reproductive health services in Kaduna, Nigeria: the role of stigma," Vulnerable Child. Youth Stud., vol. 15, no. 3, pp. 246-256, 2020.

[5] C. Donahue, "Adolescent access to and utilisation of health services in two regions of Côte d'Ivoire: A qualitative study," Glob. Public Health, vol. 14, no. 9, pp. 1302-1315, 2019.

[6] H. Awang, "Adolescent-friendly health services in primary healthcare facilities in Malaysia and its correlation with adolescent satisfaction level,” Int. J. Adolesc. Youth, vol. 25, no. 1, pp. 551-561, 2020.

[7] I. Goicolea, "Developing and sustaining adolescent-friendly health services: A multiple case study from Ecuador and Peru," Glob. Public Health, vol. 12, no. 8, pp. 1004-1017, 2017.

[8] J. M. Z. Theresa Nkole, Mukatimui Kalima Munalula, "Adolescent-Friendly Health Services in Public Health Facilities in Lusaka, Zambia,” USAID, Meas. Eval., no. April, pp. 1-34, 2019.

[9] M. Kumwenda, "Health care needs assessment among adolescents in correctional institutions in Zambia: An ethical analysis," BMC Health Serv. Res., vol. 17, no. 1, 2017. 